\title{
Research on the Water Environment Pollution Source Investigation and Control Technology During the Highway Construction Period of Qiandao Lake District
}

\author{
Zhang Dong, ${ }^{1,}$, Liu Ming $^{2}$, Wang Xiao ${ }^{1}$, Zhao Wei $^{1}$ \\ ${ }^{1}$ Research Institute of Highway Ministry of Transport \\ ${ }^{2}$ Hangzhou Qianhuang Expressway Co., Ltd, Zhejiang Province Hangzhou
}

\begin{abstract}
According to the water environment protection requirements for the Expressway Project of Qiandao Lake Area, this research combines on-site investigation with experimental detection and analysis to sort out the pollution generation link during the project construction in a systematic and comprehensive manner, analyze the source of construction sewage and wastewater, proposes special measures for sewage and wastewater treatment in the production at the precast mixing plant, bridge construction and tunnel construction. The research has achieved the goal of satisfactory sewage discharge and zero sewage discharge in the construction area, effectively ensured the safety of the water environment in the lake area during the project construction, and laid a solid foundation for Qianhuang Expressway to become a "Green Highway" demonstration project initiated by the Ministry of Transport.
\end{abstract}

CLC No.: U491 Document Code: B

\section{Introduction}

As extremely precious high-quality freshwater resources in China and also strategic sources for drinking water in the Yangtze River Delta, the water bodies of Qiandao Lake and of the upper reaches of Xin'an River are vital to the water environment safety and ecological environment protection. The Chun'an Section of Qiandao LakeHuangshan Expressway (hereinafter referred to as "Qianhuang Expressway") Project is located within the Chun'an Grade II Water Source Protection Zone of Xin'an River. The ecological and water environments along the route of this section are sensitive, and there is a high requirement for safety level of the water environment. To this end, among the first "Green Highway" demonstration projects initiated by the Ministry of Transport, Qianhuang Expressway, with water environment safety protection as its characteristic, has given pioneering demonstrations in the environmental protection and water environment safety protection of highway construction in the reservoir area of China.

With the continuous increase of expressway mileage and expansion of road network scale, highway construction is gradually facing many difficulties, such as increasingly complex geological conditions, higher percentage of bridges and tunnels and difficult project construction difficulty. Meanwhile, increasingly stricter requirements for ecological environment protection are raised. The construction involves complex process, which may cause an irreversible impact on the surrounding ecological environment if not properly handled. Thus, it is particularly important to practice the concept of green highway construction and strengthen the research on the water and soil conservation and environmental protection in highway construction. By combining the characteristics of the Yunshan Dongjiang Bridge of Huizhou City, Chen Zhigao [1] put forward an environment-friendly construction plan for water projects. By taking the construction of the Hengjiang Reservoir Extra Large Bridge in the Hengjiang Reservoir Water Source Protection Area in Jieyang, Guangdong as an example, She Mingxing [2] discusses the key points for environmental protection as well as water and soil conservation in the bridge construction of the water source protection area. By taking the Nanyi Expressway passing through the Dongting Lake as an example, Zhang Yi ${ }^{[3]}$ studied the sewage and wastewater treatment technology during the construction and operation periods to provide technical guarantee for the ecological safety of the water environment in the Dongting Lake area. By combining the characteristics of the Renbo Green Highway, Huang Can et al. [4] analyzed the sewage characteristics of the construction area and put forward effective treatment measures.

By combining the water environment sensitivity and high water environment protection requirements, this paper systematically analyzes the construction links and process that may produce obvious or potential water environment pollution, and carries out systematic water pollution prevention technology research and demonstration in a targeted way. In order to strengthen the environmental management during the process of building the highway, we have carried out surface environment monitoring, selected the corresponding monitoring sites,

*d.zhang@rioh.cn

(c) The Authors, published by EDP Sciences. This is an open access article distributed under the terms of the Creative Commons Attribution License 4.0 
made continuous site sampling, detection and analysis of their water quality, timely and accurately understood the water environment quality conditions, providing a scientific basis for effectively guaranteeing the water environment safety of Qiandao Lake.

\section{Project Overview}

Qianhuang Expressway starts from the point near Weiping Town at the junction of Zhejiang Province and Anhui Province, and ends till the Qiandao Lake Branch of Huangzhou-Xin'an-Jingdezhen Expressway. With a total length of $51.422 \mathrm{~km}$, this section is an important part of G4012 Liyang-Ningde National Expressway and an important channel for communicating Zhejiang and Anhui, Hangzhou and Huangshan. This project is a standard twoway four-lane expressway, with a designed running speed of $80 \mathrm{~km} / \mathrm{h}, 43$ bridges, 27 tunnels, five interchanges, one toll gate and one parking area on the main line. The main features of the project is described as follows:

(1) The project has a high percentage of bridges and tunnels, $78.8 \%$ of the total millage.

(2) The project has complex topographical and geological conditions along the route, high mountains, deep water, narrow construction site and many constraints on transportation.

(3) The project passes through the Qiandao Lake 5Alevel scenic spot and the second-level water source protection area. Sensitive to the environment and with high environmental requirements, it is included by the Ministry of Transport into the list of typical demonstration projects for "Green Highway" construction by the Ministry of Transport.

\section{Analysis on the main sources of sewage and wastewater during the construction of the Qianhuang Expressway}

In view of the high percentage of bridges and tunnels, complex terrain conditions, and sensitive water environment, etc. along the route of the project, the link of sewage generation during the wading bridge construction, tunnel construction and prefabricated mixing plant production is analyzed in detail and the process flow that may produce obvious or potential water environment pollution is clarified in terms of building materials stacking, production to construction to provide some basis for the implementation of the water pollution prevention and control technology and essentially protect the water environment quality of Qiandao Lake.

\subsection{Analysis on the sewage produced in the wading bridge production}

The construction process of the wading bridge is mainly divided into pile foundation operation, pile cap and pier construction as well as box girder construction, etc. The bored pile construction method is adopted for pile foundation operation. In order to facilitate the construction of bridges and the transportation of machinery and materials, a construction trestle shall be firstly erected on the river. Transport the steel casing for the pile foundation to the pier through the built construction trestle. Use a vibrating hammer to drive the steel casing for the pile foundation to the design depth. Then, install a drilling rig on the drilling pile cap to drill a hole in the steel casing until the hole reaches the required depth, clear the hole and drain the mud out. Next, sink the reinforced cage into the hole of the pile foundation and pour underground concrete.

Upon the completion of bottom sealing using concrete, pour the pile cap and the pier. The pile cap adopts the double-wall hanging box coffer dam construction. The construction process is as follows: steel casing installation $\rightarrow$ pumping $\rightarrow$ casing bottom plate installation $\rightarrow$ pouring of bottom-sera led concrete $\rightarrow$ tying the steel bars of the pile cap $\rightarrow$ pouring pile cap concrete. The pier is built by the climbing formwork method.

During the construction of the bridge coffer dam, pollutants mainly come from the construction of the water construction platform, steel coffer dam construction, bored pile construction, coffer dam pumping, construction platform removal and other links. These links cause the disturbance of sediments on the bottom of the river bed and added concentration of suspended solids in the local water area near the coffer dam. Anyhow, this impact on the water body is temporary due to the short coffer dam process.

Drilling construction is to erect a drilling rig and a circulated mud purification system on the pre-built steel coffer dam working platform and then to perform drilling operations inside the orifice casing. The drilling rig operation exchanges nothing with the external water body. However, the drilling waste sag, if improperly dealt with, would cause certain pollution to the water body. When the drilled hole meets the required depth and quality, the cleared drilling waste sag, if improperly handled, would cause leakage and pollution to the surrounding water body.

When pouring underground concrete, a certain amount of mud may overflow in the well hole and will cause pollution to the surrounding water body if no proper drainage measures are taken.

Meanwhile, oil spills or white pollution caused by improper mechanical protection during the construction process may cause great pollution to the surrounding water environment.

According to the bridge construction link, the sewage generation link during the bridge construction is shown in Figure 1. 


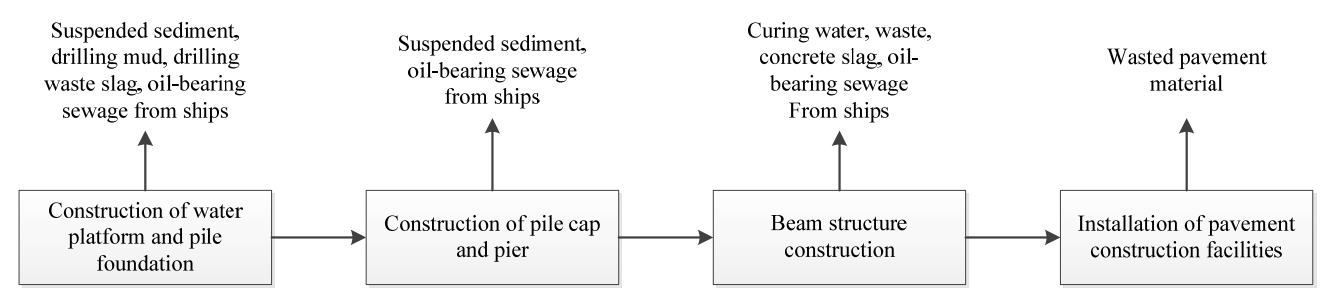

Figure 1 Schematic diagram of the sewage generation link during the bridge construction

\subsection{Installation of sewage generation during the tunnel construction}

Tunnel works mainly include tunnel construction, tunnel excavation, tunnel lining construction, tunnel waterproof and drainage construction, secondary lining construction, tunnel pavement construction, fireproof tunnel coating, as well as mechanical and electrical equipment installation.

The main sources of wastewater from tunnel construction mainly include: (1) the gushing water generated when the tunnel traverses unfavorable geological units, which may also cause changes of the groundwater environment; (2)the wastewater generated during the drilling rig construction; (3)the wastewater generated for dust reduction after the tunnel blasting; (4) wastewater generated from cleaning the rock surface before spraying the concrete; (5) wastewater from sprayed concrete and grouting, and bedrock fissure water.

\subsection{Analysis of the sewage generation link during the pre-mixing plant production}

The whole route of the project has six bid sections. According to the construction concept of "standardization, industrialization and assembly", each bid section is equipped with a prefabricated mixing plant, including sand and gravel storage area, mixing are, prefabricated beam area, beam storage area, steel bar processing area, transportation machinery storage area, etc., all of which adopt enclosed management. A large amount of sewage is inevitably generated during the production and operation of the prefabricated mixing plant and it mainly includes:

(1) wastewater generated when washing transportation vehicles, mechanical equipment, sand and gravel: This kind of wastewater contains not only sand, gravel, cement and other conventional building materials, but also various concrete additives, petroleum pollutants, etc. If directly discharged, it will cause serious pollution to the natural environment.

(2) cement, flying ash, mineral slag, admixtures and other fine-grained bulk materials: If improperly stacked and not well covered, they will cause dust or enter the water body nearby after being scoured by rainwater.

(3) The batching machine, loading bin, mixing equipment and conveying equipment in the mixing plant are very easy to generate dust. So, a certain amount of wastewater will also be produced during the water spraying and dust control process.

\section{Special measures for the prevention and control of water environment pollution during the construction of Qianhuang Expressway}

\subsection{Water pollution prevention and control measures for bridge construction}

In order to prevent the fuel of the pile foundation construction machinery from spilling, overflowing, dripping and leaking and facilitate the removal of the spilled oil, oil fences are arranged around the pile foundation construction platform to prevent oil layers from spreading and causing pollution to the water quality of Qiandao Lake, as shown in Figure 2.

The mud circulation system is adopted for rapid separation of mud and slag and full circulation of mud. A mud-slag separation and circulation tank is arranged on the construction platform. The waste mud is collected and transported to the designated tank by a special mud truck, and then processed in a unified way after drying. The surrounding area is greened as well. No waste mud is allowed to be drained into the local urban pipe network and to pollute the local environment.

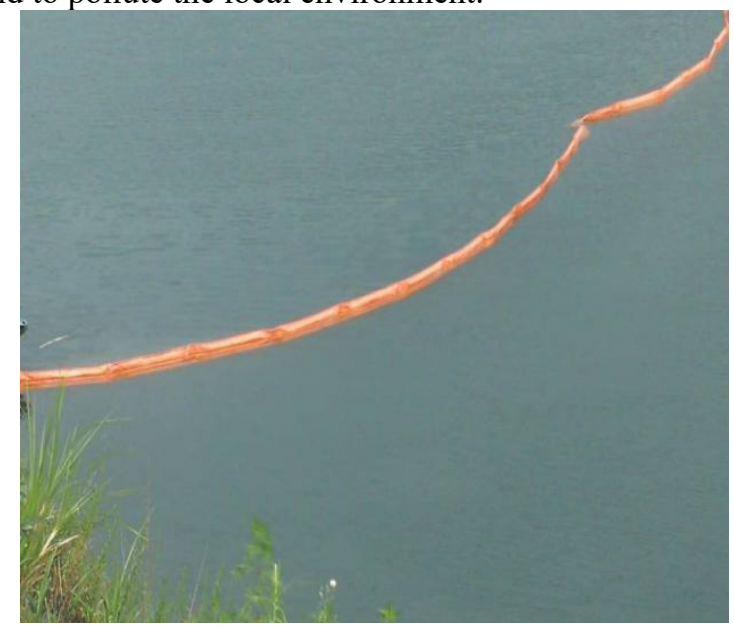

Figure 2 Oil fences

\subsection{Water pollution prevention and control measures during the tunnel construction}

In view of the fact that some sewage will be generated during the tunnel construction, such as concrete drilling, blasting and spraying, pavement cleaning, concrete curing, a sedimentation tank and an oil separating tank are provided at the entrance and exit of the tunnel, as shown in Figure 3, so that the effluent will overflow and be 
discharged after sedimentation and purification. In order to ensure the normal operation of the sedimentation tank, the sediment at the bottom of the sedimentation tank shall

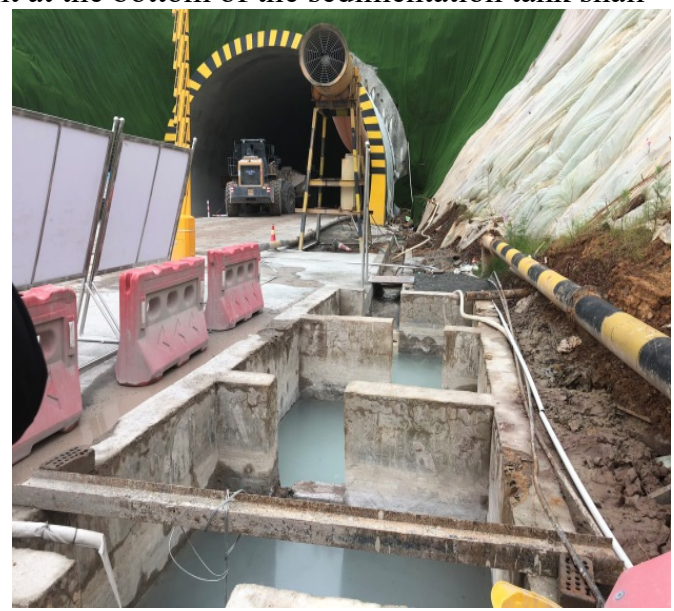

be regularly removed, and the oil separating tank with high oil content shall be deoiled.

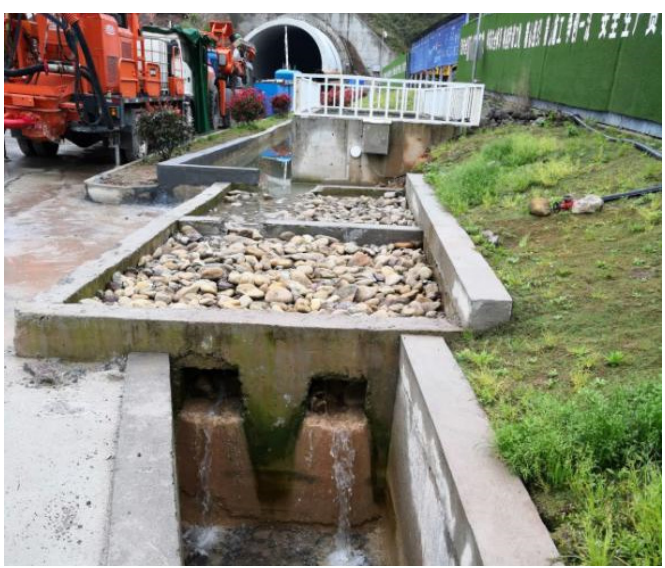

Figure 3 The sedimentation tank at the entrance and exit of the tunnel

\subsection{Treatment measures for zero discharge from the pre-mixing plant}

The green highway implementation plan is strictly implemented at the mixing plant of the prefabrication yard. Special environmental design is conducted for each bid section. Multiple types of environmental equipment are adopted. A sewage treatment center is built and includes concrete transportation fleet unloading chute, sand and gravel separator, sewage sedimentation tank, sewage tank agitator, clarification tank, conveying pump and filter press. A three-stage sedimentation tank is provided. And an intelligent spraying health-preserving system is also provided for zero discharge of production sewage from the mixing plant.

The waste slurry generated from the sand-gravel separator, the sewage from the cleaning of transportation vehicles and the dust removal of site washing, etc. flow into the sewage tank through the drainage ditch in the mixing plant, and the agitator installed in the sewage tank rotates and stirs at a uniform speed. The sewage is sucked into the filter press for treatment by the water pump and separated into mud cakes and clean water. The mud cakes can be used for construction access building and maintenance. The clean water is circulated into the collecting basin for recycling. The sewage treatment process in the mixing plant is shown in the figure.

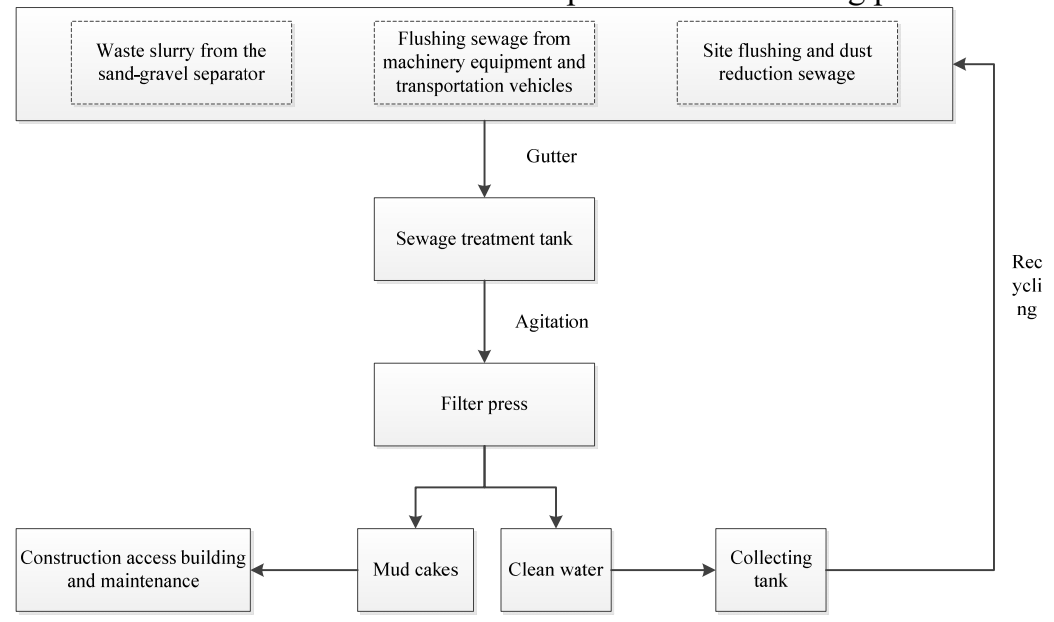

Figure 4 The zero sewage discharge process in the mixing plant

\section{Monitoring of sewage and wastewater quality during the construction of Qianhuang Expressway}

\subsection{Selection of surface water monitoring points}

Surface water monitoring points are generally selected from major rivers within $200 \mathrm{~m}$ at both sides of the highway centerline. The waters from $100 \mathrm{~m}$ upstream to
$1,000 \mathrm{~m}$ downstream from the bridge location and across rivers and lakes (drinking water source sections). There shall be no other areas around the selected points, which can reflect the pollution characteristics of the local area. And the sampling process shall be operable.

The surface water environment monitoring points in this project are located at Linqi Navigation Channel, Yunchang Navigation Channel, Hongping Navigation Channel and Lingfang Navigation Channel. The monitoring items include $\mathrm{PH}$, total phosphorous (TP), petroleum, dissolved oxygen (DO), potassium 
permanganate index, ammonia nitrogen (NH3-N), water temperature and suspended solids (SS), totaling 8 items.
Table 1 summarizes the specific monitoring items.

Table 1 Points and items for surface water environment monitoring

\begin{tabular}{|c|c|c|c|c|c|}
\hline SN & $\begin{array}{l}\text { Monitoring } \\
\text { point }\end{array}$ & Section name & Monitoring item & $\begin{array}{l}\text { Water quality } \\
\text { goal }\end{array}$ & $\begin{array}{l}\text { Monitoring } \\
\text { frequency }\end{array}$ \\
\hline 1 & $\begin{array}{c}\text { Linqi } \\
\text { Navigation }\end{array}$ & $\begin{array}{c}100 \mathrm{~m} \text { upstream } \\
1.000 \mathrm{~m}\end{array}$ & \multirow{8}{*}{$\begin{array}{l}\mathrm{pH} \text {, total phosphorus } \\
(\mathrm{TP}), \text { petroleum, } \\
\text { dissolved oxygen } \\
\text { (DO), potassium } \\
\text { permanganate index, } \\
\text { ammonia nitrogen } \\
\left(\mathrm{NH}_{3}-\mathrm{N}\right) \text {, water } \\
\text { temperature, } \\
\text { suspended solids (SS) }\end{array}$} & \multirow{8}{*}{$\begin{array}{c}\text { Environmental } \\
\text { Quality } \\
\text { Standards for } \\
\text { Surface Water } \\
\text { Class II }\end{array}$} & \multirow{8}{*}{$\begin{array}{l}\text { Four times per year, } \\
\text { continuously } \\
\text { monitored each time, } \\
\text { and once a day for } \\
\text { each section; the } \\
\text { frequency of the } \\
\text { bridge foundation } \\
\text { construction stage } \\
\text { can be increased } \\
\text { according to the } \\
\text { actual conditions. }\end{array}$} \\
\hline & Channel & downstream & & & \\
\hline 2 & $\begin{array}{l}\text { Yunchang } \\
\text { Navigation }\end{array}$ & $\begin{array}{c}100 \mathrm{~m} \text { upstream } \\
1,000 \mathrm{~m}\end{array}$ & & & \\
\hline & Channel & downstream & & & \\
\hline & Hongping & $100 \mathrm{~m}$ upstream & & & \\
\hline 3 & $\begin{array}{c}\text { Navigation } \\
\text { Channel }\end{array}$ & $\begin{array}{c}1,000 \mathrm{~m} \\
\text { downstream }\end{array}$ & & & \\
\hline & Lingfang & $100 \mathrm{~m}$ upstream & & & \\
\hline 4 & $\begin{array}{l}\text { Navigation } \\
\text { Channel }\end{array}$ & $\begin{array}{c}1,000 \mathrm{~m} \\
\text { downstream }\end{array}$ & & & \\
\hline
\end{tabular}

district highway (2020-GCKY-01)

\subsection{Upstream and downstream water quality monitoring in the wading bridge construction area}

Water quality monitoring was carried out in different months with the upstream and downstream waters in the Jinfeng Bridge, Hukeng Village Bridge and Niuwukou Bridge construction areas as representatives. According to the monitoring results, most of the monitoring items satisfy the Environmental Quality Standards for Surface Water Class II. The occasional over-standard in some individual indicators is not sustainable, indicating a good trend of overall water environment quality.

\section{Conclusions}

By taking Qianhuang Expressway as an example and combining the characteristics of the project, this paper sorts the sewage generation link during the project construction in a comprehensive and systematic manner and identifies the sources for production sewage and wastewater generated from construction. In order to protect the water environment quality to the largest extent, a series of comprehensive water resources protection technologies, including drilling waste slag and slurry circulation system, tunnel inlet and outlet oil-separating tank and sedimentation tank, mixing plant sewage and wastewater recycling, etc., are implemented for zero sewage discharge in the construction area. According to the water environment monitoring results of sensitive points, most of the monitoring items meet the Environmental Quality Standards for Surface Water Class II, which fully demonstrates that the comprehensive water environment protection technology protects the water safety of Qiandao Lake in a practical and effective way, also provides a technical reference for road building projects in identical water environment sensitive areas.

\section{Acknowledgement}

Scientific research projects of Zhejiang Provincial Department of Communications: Technologies of green environmental protection and operation safety of lake

\section{References}

1. Chen Zhigao. Environmental Construction Plan on the Road and Bridge Water Projects [J]. Guandong Highway Communications, 2013, No. 125(02):30-32.

2. She Mingxing. The Technical Innovation and Research Application of Soil and Water Conservation and Environmental Protection for Bridge Construction in Water Source Protection Areas [J]. China Standardization, 2017, No. 498(10):183+185.

3. Zhang Yi. The Comprehensive Application of Water Environment Protection Technology in the Highway Projects of Water Source Sensitive Areas [J]. Hunan Communication Science and Technology, 2017, v.43; No. 202(03):106-109+200.

4. Huang Can, Liu Zhiqiang, Liu Geming, Jiang Haifeng, Chen Kai. Analysis on the Water Pollution Characteristics and Control Analysis in the Construction Area of Renbo Expressway [J]. Journal of Highway and Transportation Research and Development (Applied Technology), 2018, v.14; No. 162(06):314-316. 